\title{
Is Juglone the Only Naphthoquinone in Juglans regia L. with Allelopathic Effects?
}

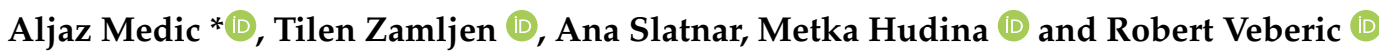 \\ Department of Agronomy, Biotechnical Faculty, University of Ljubljana, SI-1000 Ljubljana, Slovenia; \\ tilen.zamljen@bf.uni-lj.si (T.Z.); ana.slatnar@bf.uni-lj.si (A.S.); metka.hudina@bf.uni-lj.si (M.H.); \\ robert.veberic@bf.uni-lj.si (R.V.) \\ * Correspondence: aljaz.medic@bf.uni-lj.si; Tel.: +386-40240201
}

check for updates

Citation: Medic, A.; Zamljen, T.; Slatnar, A.; Hudina, M.; Veberic, R. Is Juglone the Only Naphthoquinone in Juglans regia L. with Allelopathic Effects? Agriculture 2021, 11, 784. https://doi.org/10.3390/ agriculture11080784

Academic Editor: Eiji Nishihara

Received: 2 August 2021

Accepted: 16 August 2021

Published: 17 August 2021

Publisher's Note: MDPI stays neutral with regard to jurisdictional claims in published maps and institutional affiliations.

Copyright: (C) 2021 by the authors Licensee MDPI, Basel, Switzerland. This article is an open access article distributed under the terms and conditions of the Creative Commons Attribution (CC BY) license (https:/ / creativecommons.org/licenses/by/ $4.0 /)$.

\begin{abstract}
We investigated whether juglone is the only allelochemical in a leaf extract from the walnut (Juglans regia L.). This was achieved through comparisons of the effects of pure juglone ( $1 \mathrm{mM}$, $100 \mu \mathrm{M}, 10 \mu \mathrm{M}$ control juglone) and J. regia leaf extract (prepared as $1 \mathrm{mM}, 100 \mu \mathrm{M}$ leaf juglone) on seed germination, seedling growth, and secondary metabolism of the selected crop vegetables. Two control treatments were also applied, as extraction medium and water. For inhibition of seed germination, S. lycopersicum, B. rapa var. japonica, and $V$. locusta were more sensitive to $1 \mathrm{mM}$ leaf juglone, and L. sativa was more sensitive to $1 \mathrm{mM}$ control juglone. This suggests that this walnut leaf extract contains specific phenolic substance(s) that can stimulate seed germination in some species and inhibit it in others. Seedling length was more sensitive to $1 \mathrm{mM}$ leaf juglone than $1 \mathrm{mM}$ control juglone, with selective strong inhibition of root length versus shoot length by $1 \mathrm{mM}$ control juglone. Juglone also had significant effects on the secondary metabolism of $L$. sativa, in particular for seedlings treated with $100 \mu \mathrm{M}$ control juglone, with marked decreases in all secondary metabolites studied. Flavonols constituted the majority of these metabolites in L. culinaris, which showed the least sensitivity to both control juglone and leaf juglone treatments. Thirty compounds were identified and quantified in S. lycopersicum, L. culinaris, and L. sativa, some for the first time in these plants, and all for the first time in the seedlings of these crop vegetables.
\end{abstract}

Keywords: juglone; naphthoquinones; allelopathy; Juglans regia L.; leaf extract; Solanum lycopersicum L.; Lens culinaris Medik.; Lactuca sativa L.; Brassica rapa L. var. japonica; Valerianella locusta Laterr.

\section{Introduction}

The black walnut (Juglans nigra L.) was one of the first cases of allelopathy explained [1]. Over the intervening near century, it has remained the most well-known of the allelopathic trees and the preferred cultivated species of Junglandaceae for investigations into the allelopathy of juglone (5-hydroxy-1,4-naphthoquinone) [2].

Naphthoquinones have been identified in about 20 plant families, and they are most often derived from the biosynthetic pathways for shikimic acid and o-succinoylbenzoic acid [3]. Many naphthoquinones have been demonstrated to have a broad range of toxic effects on plants, which are associated with inhibition of growth, respiration and photosynthesis, and reduced water transport [2]. Among the naphthoquinones, juglone remains of great interest due to its chemical reactivity. Metabolic studies have shown that juglone formation is the result of hydrojuglone oxidation, and that juglone can also occur as the glucoside hydrojuglone $\beta$-D-glucopyranoside [3]. Both J. nigra and Juglans regia produce these semi-water-soluble non-toxic compounds hydrojuglone and hydrojuglone $\beta$-D-glucopyranoside [1] that were previously identified in J. regia leaves, bark, buds and husk $[3,4]$. A toxic form of juglone was also previously reported from fresh J. regia leaves, roots, husks and inner root bark $[5,6]$.

Juglone is thus a characteristic compound of the Juglandaceae family. The non-toxic forms of juglone appear to be washed from the leaves by the rain, whereby in the soil they 
are oxidized to the toxic form of juglone. Thus, plants near walnut trees can be affected by the juglone that they absorb through their roots [1]. The content of juglone in the soil beneath $J$. regia trees has been reported to be from $0.25 \mathrm{mM}$ to $3.25 \mathrm{mM}$, depending on the time of the year [7].

Studies have shown that juglone can penetrate the plasma membrane of cells and induce depolarisation by blocking $\mathrm{K}^{+}$channels [3]. Juglone can inhibit shoot and root growth and nutrient uptake, and it can attack naturally occurring symbionts, thereby destroying a usable source of nutrients [1]. The high toxicity of juglone compared to other known naphthoquinones is suggested to be due to its high redox potential $(-93 \mathrm{mV})$ and high electrophilicity and thiol reactivity, which cause irreversible complexation of the cysteine-rich proteins that are important for mitosis [2].

To date, the studies carried out have generally focused on the effects of juglone itself, and few studies have investigated the effects of walnut leaf extracts in allelopathy [8]. Furthermore, these previous studies have lacked a full comparison between juglone itself and the leaf extract concentrations of juglone. These leaf extracts were not quantified for the juglone contents, as they were only diluted at different ratios, which is not precise and does not answer the question of whether the juglone is indeed the only allelochemical in the leaf extracts.

Therefore, the objective of the present study was to determine the effects of known concentrations of juglone alone and as present in a walnut leaf extract. The target system used was seed germination and seedling growth across five different vegetable crops: Solanum lycopersicum L., Solanaceae (tomato); Lens culinaris Medik., Fabaceae (lentil); Lactuca sativa L., Asteraceae (lettuce); Brassica rapa L. var. japonica, Brassicaceae (mizuna); and Valerianella locusta Laterr., Caprifoliaceae (corn salad). Furthermore, we investigated the molecular responses of these target crops over the first days of their development. The goal was also to determine whether juglone is indeed the crucial allelochemical present in such leaf extracts from J. regia, or if there are other allelochemicals that have remained 'hidden' in the shadow of juglone. As juglone was the first allelochemical discovered for walnut trees, the allelopathy effects seen are usually automatically attributed to juglone, without any specific supporting studies.

\section{Materials and Methods}

Five commonly cultivated crop vegetables were initially used here, as L. sativa, $L$. culinaris, B. rapa var. japonica, S. lycopersicum, and $V$. locusta. This range of crop vegetables was used to determine whether the control juglone and the leaf juglone had the same effects across all such plants, or whether the effects varied.

Prior to the start of the main study, initial tests were carried out to determine the relevant concentrations of pure juglone and leaf extract juglone for each of these crop vegetables. The experiments followed three particular aspects here, where the treatment conditions were the same. The experiments were carried indoors and at room temperature.

The first part investigated the effects on seed germination of control juglone and leaf juglone. The second part then examined seedling growth with the treatments designed according to the results from the seed germination. The aim was to include at least one crop vegetable that was susceptible to control juglone, one that was susceptible to leaf juglone, and one that was tolerant to both. The last part was designed to study the molecular responses to these different treatments.

\subsection{Chemicals and Plant Material}

The seeds used were as follows: Lactuca sativa L. 'Grazer Krauthauptel 2', Lens culinaris Medik., Brassica rapa L. var. japonica 'Mizuna grun', and Valerianella locusta Laterr. (Austrosaat AG, Wien, Austria); and Solanum lycopersicum L. 'Novosadski Jabučar' (Semenarna Ljubljana, Ljubljana, Slovenia). All of the seeds were designated for planting in 2021.

The following standards were used to identify and quantify the phenolics: kaempferol3-glucoside, quercetin-3-glucoside, p-coumaric acid (Fluka Chemie GmbH, Buchs, Switzer- 
land); chlorogenic acid (trans-5-caffeoylquinic acid), neochlorogenic acid (3-caffeoylquinic acid), cryptochlorogenic acid (4-caffeoylquinic acid), juglone (5-hydroxy-1,4-naphthoquinone), caffeic acid, gallic acid (Sigma-Aldrich Chemie GmbH, Steinheim, Germany).

The water used in the preparation of all of the samples, solutions and analyses was bi-distilled and purified using a Milli-Q water purification system (Millipore, Bedford, MA, USA). The chemicals for the mobile phases for the gradients for the mass spectrometry analysis (acetonitrile, formic acid) were HPLC-MS grade (Fluka Chemie GmbH, Buchs, Switzerland), as was the methanol for the phenolics extraction (Sigma-Aldrich, Steinheim, Germany).

\subsection{Preparation of J. Regia Leaf Extract}

The leaves for the leaf extract were obtained on 10 September 2020, from a 24-year-old J. regia tree grown among others at a planting density of $10 \mathrm{~m} \times 10 \mathrm{~m}$. It belonged to the French cultivar 'Franquette', which has been the most commonly studied and used in research. The leaves were collected from the south side of the tree, from the middle part of the canopy. The leaves were placed into a paper bag, frozen with liquid nitrogen, and then lyophilized. After lyophilization, the leaves were ground using a mortar and pestle, and added to the extraction medium containing $0.17 \%$ DMSO (Dimethyl sulfoxide) and $0.17 \% \mathrm{EtOH}$ (ethanol) in $\mathrm{H} 2 \mathrm{O}$ (water). The extraction was carried out in an ultrasonic bath (Sonis 4; Iskra Pio, Šentjernej, Slovenia) filled with ice, for $60 \mathrm{~min}$, with the extraction then centrifuged at $10,000 \times g$ for $10 \mathrm{~min}$ at $4{ }^{\circ} \mathrm{C}$ (5810 R; Eppendorf, Hamburg, Germany). A sample was taken from the extract (i.e., supernatant) for juglone quantification by HPLCMS. The samples were then diluted to prepare the required leaf extracts with $1 \mathrm{mM}$ and $100 \mu \mathrm{M}$ juglone (here referred to as the 'leaf juglone'). Parallel juglone solutions were prepared from juglone dissolved in the extraction medium ( $0.17 \%$ DMSO, $0.17 \%$ ethanol in $\mathrm{H}_{2} \mathrm{O}$ ) to the same final juglone concentrations as for the leaf juglone (here referred to as the 'control juglone'). The inclusion of DMSO and ethanol in the extraction was due to the final required concentration of $1 \mathrm{mM}$ juglone. Unlike indications from previous studies [9-11], the low solubility of juglone in water alone $(52 \mathrm{mg} / \mathrm{L})$ means that the juglone in the required solution for $1 \mathrm{mM}$ juglone final concentration $(174.15 \mathrm{mg} / \mathrm{L}) \mathrm{did}$ not completely dissolve in water alone.

\subsection{Seed Germination}

The seeds form the five different crop vegetables were treated with: (i) two control treatments, as one with the extraction medium $\left(0.17 \%\right.$ DMSO, $0.17 \% \mathrm{EtOH}$ in $\left.\mathrm{H}_{2} \mathrm{O}\right)$, referred to as $\mathrm{K} 1$ and the other with water, referred to as K2. (ii) juglone prepared for the final concentrations of $1 \mathrm{mM}, 100 \mu \mathrm{M}$, and $10 \mu \mathrm{M}$ juglone prepared in the extraction medium $(0.17 \%$ DMSO, $0.17 \%$ ethanol in water); (iii) juglone prepared from the leaf extract for the final concentrations of $1 \mathrm{mM}$ and $100 \mu \mathrm{M}$ juglone, with the extract preparation and the required dilutions carried out using the extraction medium $(0.17 \% \mathrm{DMSO}, 0.17 \%$ ethanol in water). Contrary to other studies on allelopathy where juglone was dissolved in water [9-11], in the present study, the juglone was dissolved in $0.17 \%$ DMSO and $0.17 \%$ ethanol in water. This is because juglone is only partially soluble in water $(52 \mathrm{mg} / \mathrm{L})$ and thus the required concentration of $1 \mathrm{mM}$ control juglone could not be achieved in water alone. Thus, the previously reported preparation of $1 \mathrm{mM}$ juglone could not be achieved using water. Thus, we note here that the accuracy of previous studies that have used $>100 \mu \mathrm{M}$ juglone dissolved only in water is questionable. The composition of the extraction medium used in the present study was, thus, initially testing for optimal juglone dissolution.

For the seed germination, 50 seeds per crop vegetable per replicate were placed on sterile cellulose paper in sterile Petri dishes. Ten replicates were performed for each condition. The Petri dishes had $2.5 \mathrm{~mL}$ of each experimental medium added and were sprayed with $0.5 \mathrm{~mL}$ of each medium to maintain as uniform conditions as possible, with the Petri dishes covered with their lids. To avoid drought stress and to prevent seed 
desiccation, the seeds of S. lycopersicum, L. sativa, B. rapa var. japonica, and V. locusta were sprayed with $1.0 \mathrm{~mL}$ of extract daily (i.e., 7 times), with the seeds of L. culinaris sprayed with $2 \mathrm{~mL}$ daily (i.e., 14 times), due to the larger seeds and faster drying out of the cellulose paper and seeds. The same procedure was used for all of the experiments (i.e., separately for seed measures, shoot measures, and phenolics analysis). The full germination period was monitored in relation to the growth of the seedlings, as different seeds germinated and grew faster than others, with seven to nine days of germination generally monitored.

\subsection{Seedling Length}

Following the initial experiments on seed germination with the five crop vegetables, four of them were chosen to investigate the seedling lengths. As indicated above, the aim was to use at least one crop vegetable where the seed germination was tolerant to both control juglone and leaf juglone, one that was susceptible to control juglone, and one that was susceptible to leaf juglone. $V$. locusta was not used because the seed germination was low and variable. The seeds and seedling lengths were determined every 2 days after the third day of germination, as three replicates per determination, and 20 randomly selected seedlings per Petri dish. For L. sativa and B. rapa, only three measurements were taken because the seedlings grew too large and were restricted by the lids of the Petri dishes. On the last day of the measurements, shoot and root length were measured for S. lycopersicum and L. culinaris in addition to total seedling length; this was not done for L. sativa and $B$. rapa var. japonica because of the possible restriction of the growth by the lids of the Petri dishes (see above).

\subsection{Secondary Metabolite Extraction}

For the responses to these juglone treatments in terms of the secondary metabolism of the crop vegetables, S. lycopersicum, L. culinaris, and L. sativa were used, as tolerant to control juglone and leaf juglone, susceptible to control juglone, and susceptible to leaf juglone. The seeds were prepared in the Petri dishes as described above and were sampled every 2 days to 3 days. Secondary metabolite measurements began as soon as seedlings began to germinate, and sufficient plant material was available to sample. For each sample, four replicates were used per treatment.

For the sampling, the treated seedlings were transferred from the Petri dish into water to wash off the treatment solutions, and the seed coat was removed. The seedlings were then placed in paper bags and immediately frozen with liquid nitrogen and stored in a freezer at $-20^{\circ} \mathrm{C}$ until further analysis.

In preparation for the secondary metabolite analysis, $200 \mathrm{mg}$ of each sample was extracted using 80\% methanol, 3\% formic acid in water, at a tissue:solution ratio of 1:100 $(w / v)$. The protocol followed that described previously by Medic et al. [12].

\subsection{Secondary Metabolite Analysis}

The phenolics and amino acids were analyzed on an UHPLC system (Vanquish; Thermo Scientific, Waltham, MA, USA) with a diode array detector at $350 \mathrm{~nm}$ for flavonols and at $280 \mathrm{~nm}$ for the rest of the compounds. The spectra were recorded between $200 \mathrm{~nm}$ and $600 \mathrm{~nm}$. A C18 column (Gemini $150 \times 4.60 \mathrm{~mm} ; 3 \mu \mathrm{m}$; Phenomenex Torrance, Torrance, CA, USA) was used to separate the phenolics and amino acids, at $25^{\circ} \mathrm{C}$, as previously described by Medic et al [12].

Identification of the phenolics and amino acids was carried out by tandem mass spectrometry (MS/MS; LTQ XL; Thermo Scientific, Waltham, MA, USA) with heated electrospray ionisation operating in negative ion mode. The heated electrospray ionization parameters were as follows: ion spray voltage, $3.5 \mathrm{kV}$; capillary temperature, $320{ }^{\circ} \mathrm{C}$; heater temperature, $320^{\circ} \mathrm{C}$; capillary voltage, $10.0 \mathrm{~V}$; sheath gas, $50 \mathrm{arb}$; auxiliary gas, 20 arb; and tube lens $-68.0 \mathrm{~V}$. Collision-induced dissociation was achieved using helium as the collision gas (collision energy, $30 \mathrm{eV}$ ). The mass spectrometry scanning for analysis was 
from $\mathrm{m} / \mathrm{z} 50$ to $\mathrm{m} / \mathrm{z} 2000$, with data acquisition using the Xcalibur 2.2 software (Thermo Fischer Scientific Institute, Waltham, MA, USA).

The phenolics were fragmented, and external standards were used for identification and quantification of known compounds. Literature data and mass spectrometry fragmentation were used for identification of the unknown compounds, which were then quantified using similar standards. The levels of the individual phenolics are expressed as $\mathrm{g} / \mathrm{kg}$ dry weight, with their quantification according to the most relevant standard.

\subsection{Statistical Analysis}

The data were entered into Microsoft Excel 2016, with the statistical analyses performed with R commander (R version 3.4.2, John Fox, GNU General Public License, Hamilton, ON, Canada, 2017) package Rcmdr. The data are expressed as means \pm standard error (SE). For determination of significant differences between the data, one-way analysis of variance (ANOVA) was used, with Tukey's tests. Statistical means at 95\% confidence level were calculated to determine the significances of the differences $(p<0.05)$.

\section{Results}

\subsection{Juglone Content of the Leaf Extract}

The juglone concentration of the leaf extract was initially analysed by HPLC-mass spectrometry to determine the required dilutions for the assay conditions for the leaf extract with the known final concentrations of juglone, as $1 \mathrm{mM}$ and $100 \mu \mathrm{M}$ (defined as the 'leaf juglone' samples). These leaf extracts were assayed alongside the same final concentrations (i.e., $1 \mathrm{mM}, 100 \mu \mathrm{M}, 10 \mu \mathrm{M}$ ) of juglone prepared from the pure compound dissolved in the extraction medium (i.e., $0.17 \%$ DMSO, $0.17 \%$ ethanol, in water; defined as the 'control juglone' samples). Furthermore, to also define any effects of vehicle inclusion in the assays (i.e., the extraction medium), two controls were used, as the extraction medium alone (K1) and water (K2).

\subsection{Seed Germination}

The first target was for the effects of juglone on the germination of seeds of the five crop vegetables tested: S. lycopersicum, $L$. culinaris, L. sativa, B. rapa var. japonica, and V. locusta. Figure 1 shows the data obtained for the germination rates across the control samples (K1, K2) and for the treatments with $1 \mathrm{mM}, 100 \mu \mathrm{M}$ and $10 \mu \mathrm{M}$ control juglone and $1 \mathrm{mM}$ and $100 \mu \mathrm{M}$ leaf juglone. The statistically significant differences relevant to Figure 1 are given in Supplementary Materials Table S1.

Looking at the total germinated seeds, and compared to the vehicle control (K1), significant differences were seen for the effects of juglone on these different crop vegetables, except for L. culinaris, where neither control juglone nor leaf juglone had any effects. The $1 \mathrm{mM}$ control juglone significantly reduced seed germination of L. sativa, B. rapa var. japonica, and $V$. locusta, with significantly lower proportions of seeds reaching germination as well as significant delays in seed germination. The greatest reduction was with $1 \mathrm{mM}$ control juglone for $L$. sativa. The $1 \mathrm{mM}$ leaf juglone significantly reduced the overall germination of S. lycopersicum, B. rapa var. japonica, and V. locusta, as well as the germination rates for all of these crop vegetables. The greatest reductions here for total germination were for $V$. locusta, followed by B. rapa var. japonica, and considering the germination rates, the greatest reductions were for $V$. locusta, followed by S. lycopersicum and B. rapa var. japonica. For the vehicle (K1) and water (K2) controls, germination was slightly, but significantly, reduced from K2 to K1 for S. lycopersicum, B. rapa var. japonica, and V. locusta, indicating the effects of the vehicle here. Overall, for the comparisons with the vehicle control (K1), the $10 \mu \mathrm{M}$ and $100 \mu \mathrm{M}$ treatments for both control juglone and leaf juglone did not have any significant effects on seed germination for any of these crop vegetables. 
A

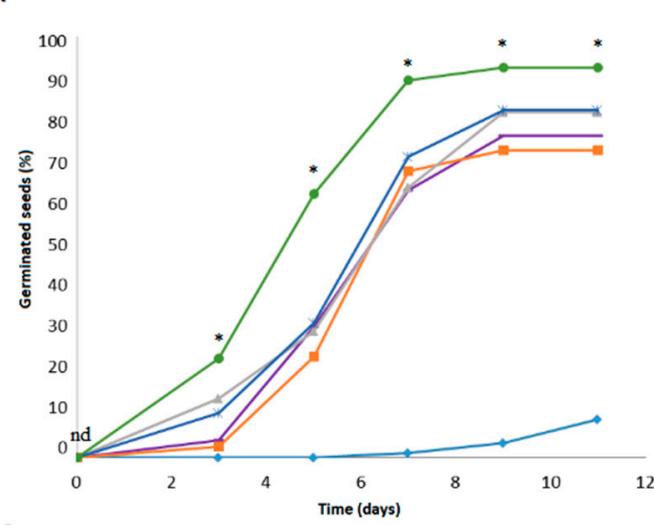

c

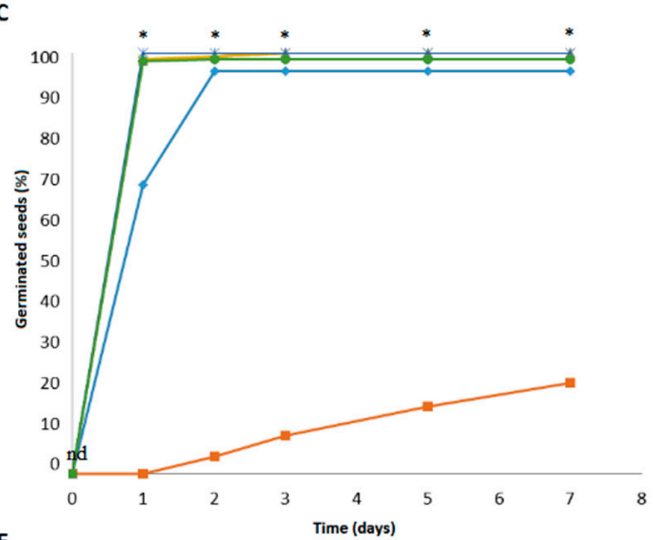

E

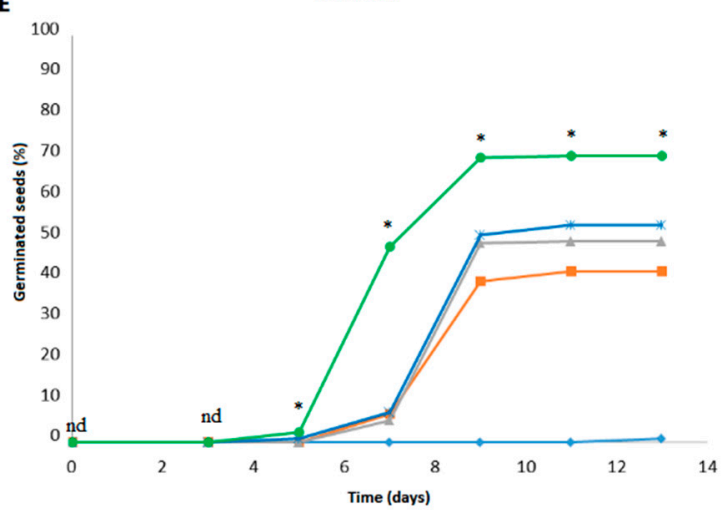

B
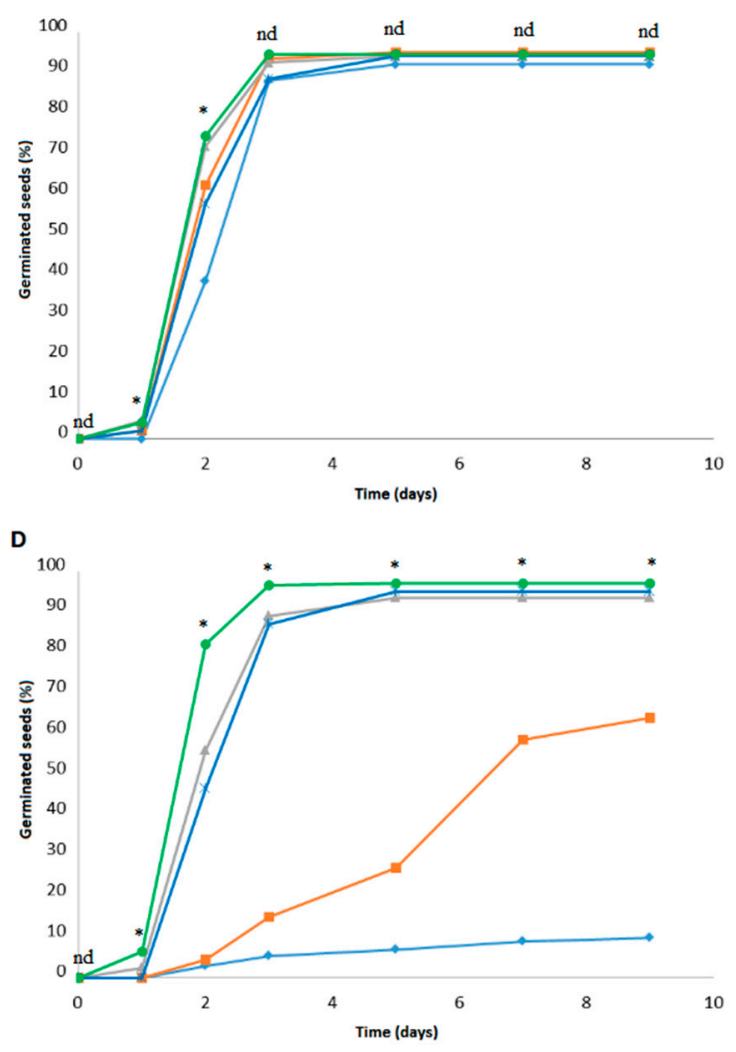

Figure 1. Effects of control juglone and known leaf extract juglone treatments on germination of seeds of S. lycopersicum (A), L. culinaris (B), L. sativa (C), B. rapa var. japonica (D) and V. locusta (E). K1, extraction medium (vehicle); K2, water; *; are significantly different $(p<0.05)$; nd, not significantly different.

\subsection{Seedling Length}

Figure 2 shows the data for the total lengths of the seedlings across the control samples $(\mathrm{K} 1, \mathrm{~K} 2)$ and for the treatments with $1 \mathrm{mM}, 100 \mu \mathrm{M}$ and $10 \mu \mathrm{M}$ control juglone and $1 \mathrm{mM}$ and $100 \mu \mathrm{M}$ leaf juglone for the four crop vegetables analysed here (i.e., S. lycopersicum, L. culinaris, L. sativa, B. rapa var. japonica). V. locusta was not included in this analysis due to poor germination rates (Figure 1E). The statistically significant differences relevant to Figure 2 are given in Supplementary Materials Table S2. 

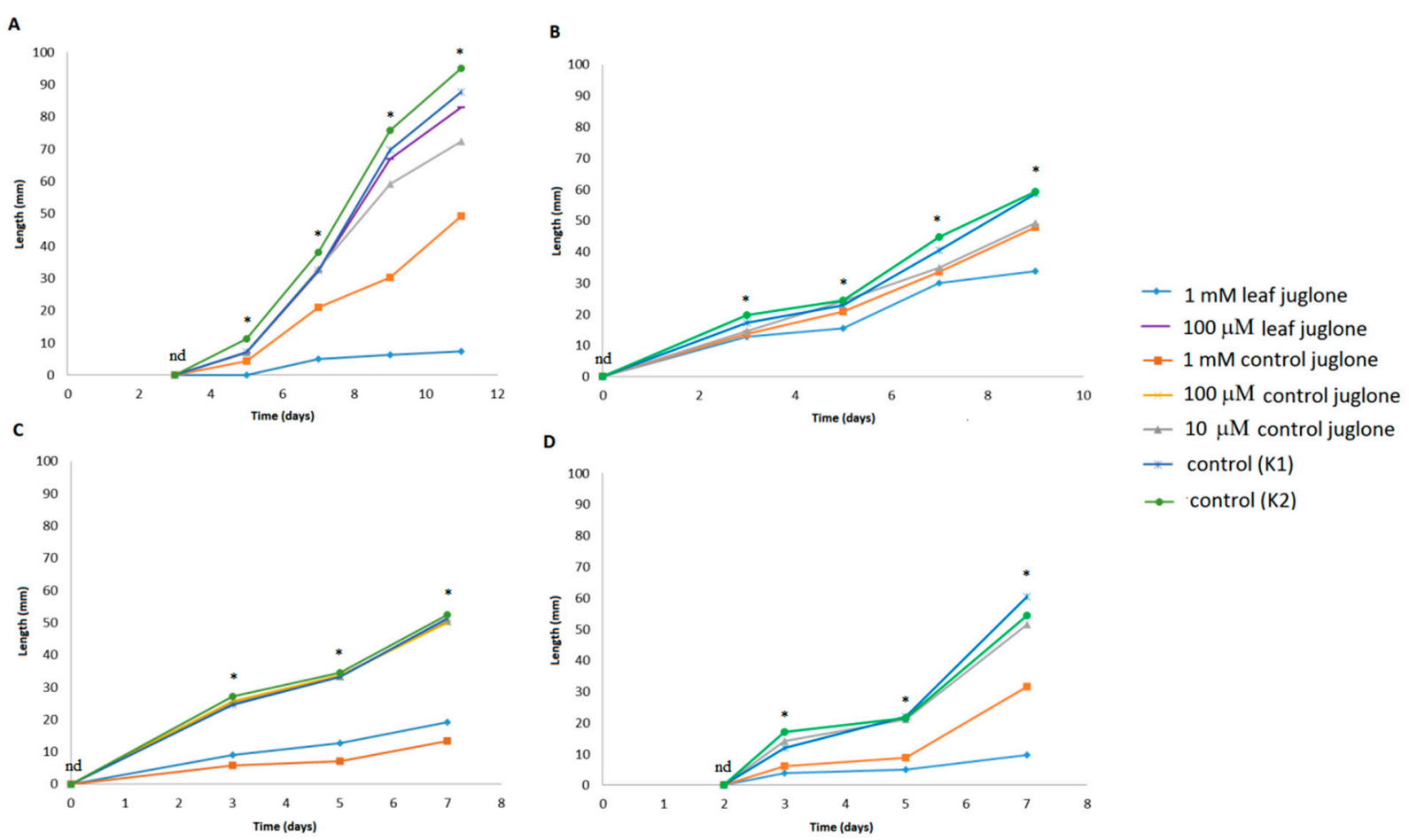

Figure 2. Effects of control juglone and known leaf extract juglone treatments on the overall lengths of the seedlings of $S$. lycopersicum (A), L. culinaris (B), L. sativa (C) and B. rapa var. japonica (D). K1, extraction medium (vehicle); K2, water; *; are significantly different $(p<0.05)$; nd, not significantly different.

Looking at these total lengths of the seedlings from the germinated seeds, compared to the vehicle control (K1), significant differences were seen for all four of these crop vegetables, as reductions generally from early times of seed germination. As previously seen for seed germination, both $1 \mathrm{mM}$ control juglone and leaf juglone significantly reduced the seedling lengths, here across all four crop vegetables, and particularly by the last days of the measurements. Figure 2 shows that $1 \mathrm{mM}$ leaf juglone significantly reduced the seedling lengths to a greater extent for S. lycopersicum, L. culinaris, and B. rapa var. japonica, while $1 \mathrm{mM}$ control juglone showed greater reductions for L. sativa. Interestingly, the seedling lengths for L. culinaris were equally reduced for $1 \mathrm{mM}$ and $10 \mu \mathrm{M}$ control juglone. In contrast to the germination effects, there were little or no differences between the water (K2) and vehicle (K1) control groups for seed lengths.

Figure 3 shows the absolute and relative separately determined shoot and root lengths across the control samples $(\mathrm{K} 1, \mathrm{~K} 2)$ and for the treatments with $1 \mathrm{mM}$ and $10 \mu \mathrm{M}$ control juglone and $1 \mathrm{mM}$ and $100 \mu \mathrm{M}$ leaf juglone for the two crop vegetables analysed here: $S$. lycopersicum and L. culinaris. The other two crop vegetables analysed for total seedling length were excluded due to limitations in the experimental set-up on the final day of the measurements (see Methods).

For S. lycopersicum, the shoot length was the shortest for $1 \mathrm{mM}$ leaf juglone, with little or no differences for the other control and juglone treatments. For L. culinaris, shoot length was also the shortest for $1 \mathrm{mM}$ leaf juglone, although smaller differences were seen here. Interestingly, although root lengths were the shortest for $1 \mathrm{mM}$ control and leaf juglone for both of these crop vegetables, as their shoot lengths were little changed for $1 \mathrm{mM}$ control juglone, this resulted in longer seedlings overall for $1 \mathrm{mM}$ control juglone compared to $1 \mathrm{mM}$ leaf juglone. For $S$. lycopersicum, although it can be seen that $1 \mathrm{mM}$ leaf juglone greatly shortened both root and shoot lengths (Figure 3A), there was a small relative elongation of the root (i.e., slightly increased root-to-shoot ratio; K2, 0.92; $1 \mathrm{mM}$ leaf juglone, 1.22) (Figure 3B). In contrast, $1 \mathrm{mM}$ control juglone resulted in the opposite, as an apparently selective effect for shorter roots with maintained shoot lengths (i.e., reduced root-to-shoot ratio; K2, 0.92; $1 \mathrm{mM}$ control juglone, 0.22) (Figure 3B). For L. culinaris, $1 \mathrm{mM}$ leaf juglone 
again appeared to affect the whole seedlings, with decreased total length (Figure 3C) but no changes in the relative proportions of root and shoot lengths (i.e., maintained root-to-shoot ratio; K2, 0.96; $1 \mathrm{mM}$ leaf juglone, 0.82 ) (Figure 3D); conversely again, $1 \mathrm{mM}$ control juglone resulted in shorter roots, but little or no effect on the shoots (i.e., reduced root-to-shoot ratio; K2, 0.96; $1 \mathrm{mM}$ control juglone, 0.47 ) (Figure 3C,D). There were no differences in the root and shoot lengths or their relative proportions between the control groups (K1, K2).
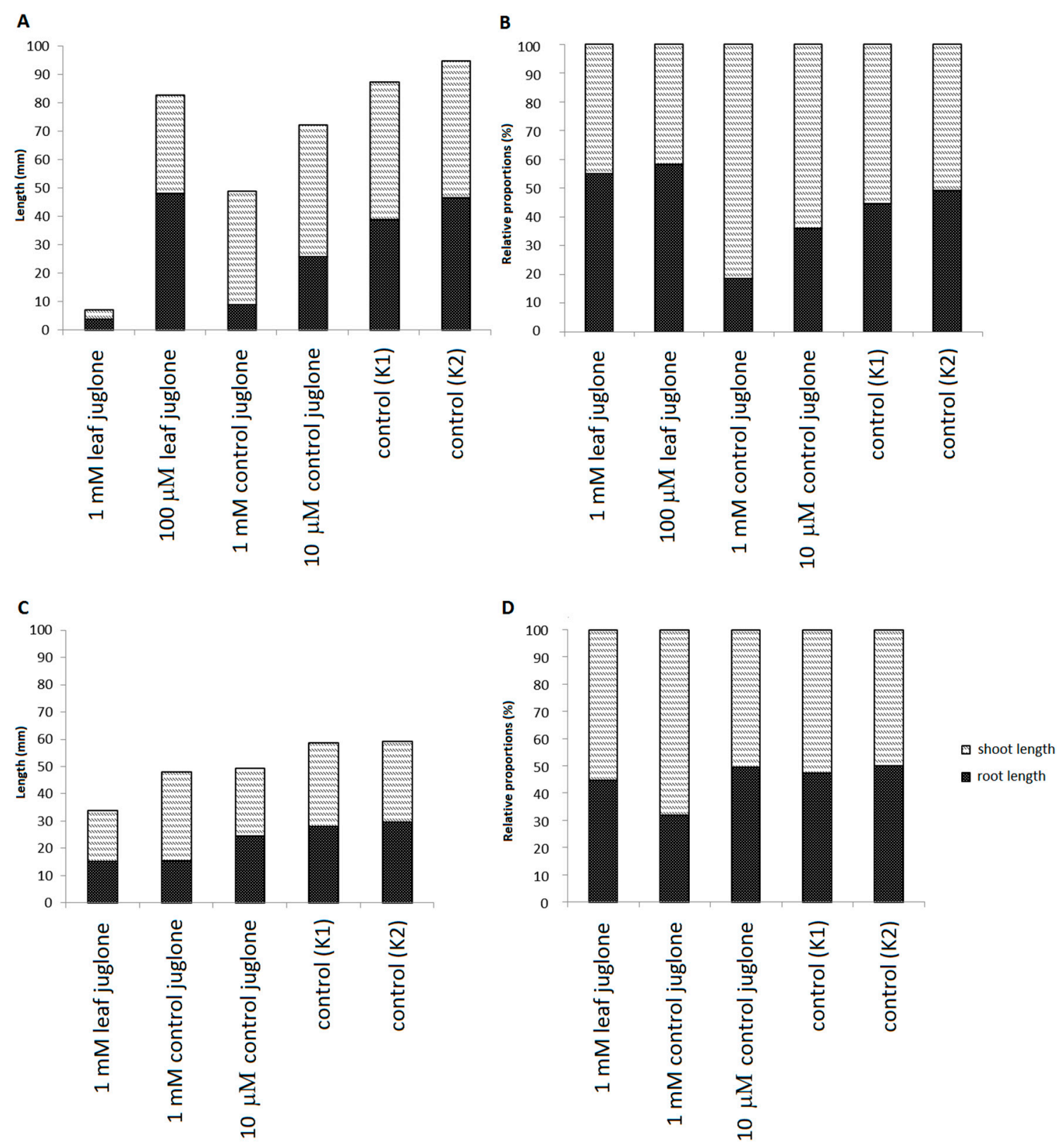

Figure 3. Effects of control juglone and known leaf extract juglone treatments on root and shoot lengths for the seedlings of S. lycopersicum $(\mathbf{A}, \mathbf{B})$ and L. culinaris $(\mathbf{C}, \mathbf{D})$ on the last day of the measurements. Both the absolute $(\mathbf{A}, \mathbf{C})$ and relative $(\mathbf{B}, \mathbf{D})$ root and shoot lengths of the seedlings are shown. K1, extraction medium (vehicle); K2, water.

\subsection{Secondary Metabolite Analysis}

The survival of plants under different adverse environmental conditions due to biotic and abiotic stresses is promoted through their production of various protective secondary metabolites $[13,14]$. Therefore, to investigate this further, three of the crop vegetables were chosen to take forward to define their profiles of secondary metabolites: one that was largely tolerant to the juglone treatments during seed germination (i.e., L. culinaris); one 
that appeared selectively sensitive to the control juglone treatment (i.e., L. sativa); and one that appeared selectively sensitive to the leaf juglone treatment (i.e., S. lycopersicum).

The compounds identified and the standards that they were based on for quantification are given in Table 1, along with the main fragmentation profiles for the tandem mass spectrometry analysis.

Table 1. Tentative identification of phenolic compounds of Lactuca sativa L., Lens culinaris Medik. and Solanum lycopersicum L., and compounds used as standard equivalents. Compounds for which no standards were obtained are identified according to literature sources.

\begin{tabular}{|c|c|c|c|c|c|c|c|}
\hline Source & Compound & $\begin{array}{l}\text { Retention } \\
\text { Time (min) }\end{array}$ & $\begin{array}{c}{[\mathbf{M}-\mathbf{H}]^{-}} \\
(\mathrm{m} / \mathrm{z})\end{array}$ & $\operatorname{MS}^{2}(m / z)$ & $\operatorname{MS}^{3}(m / z)$ & $\operatorname{MS}^{4}(m / z)$ & $\begin{array}{l}\text { Expressed as } \\
\text { (Equivalents) }\end{array}$ \\
\hline \multirow{9}{*}{$\begin{array}{l}\text { Lactuca } \\
\text { sativa }\end{array}$} & $\begin{array}{l}\text { 4-Hydroxyphenylaoyl glucoside } \\
\text { derivative }\end{array}$ & 7.18 & 359 & 313 & $151,269,185$ & \multirow{9}{*}{$\begin{array}{l}185,169 \\
198,157\end{array}$} & Gallic acid \\
\hline & $\begin{array}{l}\text { Neochlorogenic acid } \\
\text { (3-caffeoylquinic acid) }\end{array}$ & 9.18 & 353 & $191,179,135$ & & & $\begin{array}{l}\text { Neochlorogenic } \\
\text { acid }\end{array}$ \\
\hline & Dihydroxybenzoic acid hexoside & 9.35 & 315 & 153,108 & & & Gallic acid \\
\hline & $\begin{array}{c}\text { Chlorogenic acid } \\
\text { (trans-5-caffeoylquinnic acid) }\end{array}$ & 12.37 & 353 & $191,179,135$ & & & Chlorogenic acid \\
\hline & Caffeic acid & 14.24 & 179 & 135,89 & & & Caffeic acid \\
\hline & Quercetin-3-O-glucoronide & 21.23 & 477 & 301 & 179,151 & & $\begin{array}{l}\text { Quercetin-3-O- } \\
\text { glucoside }\end{array}$ \\
\hline & 3,5-Dicaffeoylquinic acid & 22.57 & 515 & 353 & $191,179,135$ & & $\begin{array}{l}\text { Neochlorogenic } \\
\text { acid }\end{array}$ \\
\hline & Lactucin-15-oxalate & 24.74 & 347 & 275,257 & 213,257 & & Gallic acid \\
\hline & Caffeoyltartaric acid hexoside & 25.92 & 473 & 311,293 & 179,149 & & Caffeic acid \\
\hline \multirow{11}{*}{$\begin{array}{l}\text { Lens } \\
\text { culinaris }\end{array}$} & Phenyl butryryl glutamine & 10.01 & 291 & $\begin{array}{c}171,127,145 \\
119,222\end{array}$ & & \multirow{4}{*}{$\begin{array}{c}151,257 \\
241,213,267 \\
285,575\end{array}$} & Gallic acid \\
\hline & $\begin{array}{l}\text { Kaempferol dirhamnoside } \\
\text { dihexoside } 1\end{array}$ & 13.76 & 901 & 755,285 & 285,575 & & $\begin{array}{l}\text { Kaempferol-3- } \\
\text { glucoside }\end{array}$ \\
\hline & $\begin{array}{l}\text { Kaempferol glycoside. acylated } \\
\text { hexoside }\end{array}$ & 16.87 & 1093 & 931 & $755,631,285$ & & $\begin{array}{l}\text { Kaempferol-3- } \\
\text { glucoside }\end{array}$ \\
\hline & $\begin{array}{l}\text { Kaempferol rhamnoside } \\
\text { dihexoside }\end{array}$ & 17.15 & 755 & 285,575 & $\begin{array}{c}151,257,241,213 \\
267\end{array}$ & & $\begin{array}{l}\text { Kaempferol-3- } \\
\text { glucoside }\end{array}$ \\
\hline & Kaempferol glycoside. acylated 1 & 17.81 & 931 & 755,285 & 285,609 & $\begin{array}{c}151,257 \\
241,213,267\end{array}$ & $\begin{array}{l}\text { Kaempferol-3- } \\
\text { glucoside }\end{array}$ \\
\hline & $\begin{array}{l}\text { Kaempferol glycoside. acylated } \\
\text { rhamnoside } 1\end{array}$ & 18.65 & 1077 & 931 & 755,285 & 285 & $\begin{array}{l}\text { Kaempferol-3- } \\
\text { glucoside }\end{array}$ \\
\hline & $\begin{array}{c}\text { Kaempferol trirhamnoside } \\
\text { dihexoside } 1\end{array}$ & 18.93 & 1047 & 901 & 755,285 & 285 & $\begin{array}{l}\text { Kaempferol-3- } \\
\text { glucoside }\end{array}$ \\
\hline & $\begin{array}{l}\text { Kaempferol glycoside. acylated } \\
\text { rhamnoside } 2\end{array}$ & 19.11 & 1077 & 931 & 755,285 & 285 & $\begin{array}{l}\text { Kaempferol-3- } \\
\text { glucoside }\end{array}$ \\
\hline & $\begin{array}{l}\text { Kaempferol trirhamnoside } \\
\text { dihexoside } 2\end{array}$ & 19.34 & 1047 & 901 & 755,285 & 285 & $\begin{array}{l}\text { Kaempferol-3- } \\
\text { glucoside }\end{array}$ \\
\hline & Kaempferol glycoside. acylated 2 & 21.65 & 931 & 755,285 & 285,609 & $\begin{array}{c}151,257 \\
241,213,267\end{array}$ & $\begin{array}{l}\text { Kaempferol-3- } \\
\text { glucoside }\end{array}$ \\
\hline & $\begin{array}{l}\text { Kaempferol dirhamnoside } \\
\text { dihexoside } 2\end{array}$ & 21.99 & 901 & 755,285 & 285,575 & $\begin{array}{c}151,257 \\
241,213,267\end{array}$ & $\begin{array}{l}\text { Kaempferol-3- } \\
\text { glucoside }\end{array}$ \\
\hline \multirow{12}{*}{$\begin{array}{c}\text { Solanum } \\
\text { lycopersicum }\end{array}$} & Caffeoyl hexaric acid 1 & 7.06 & 371 & \multirow{2}{*}{$\begin{array}{c}209,191 \\
171,127,145 \\
119,222\end{array}$} & \multirow[t]{2}{*}{191,85} & & Caffeic acid \\
\hline & Phenyl butryryl glutamine & 9.65 & 291 & & & & Gallic acid \\
\hline & Caffeoyl hexaric acid 2 & 9.83 & 371 & 209,191 & \multirow{3}{*}{$\begin{array}{l}191,85 \\
113\end{array}$} & & Caffeic acid \\
\hline & Decatylosperuloside derivative 1 & 10.94 & 349 & 249 & & & Gallic acid \\
\hline & Caffeic acid hexoside & 11.34 & 341 & 179,135 & & & Caffeic acid \\
\hline & Decatylosperuloside derivative 2 & 11.97 & 351 & 249 & \multirow[t]{4}{*}{113} & & Gallic acid \\
\hline & $\begin{array}{c}\text { Chlorogenic acid } \\
\text { (trans-5-caffeoylquinnic acid) }\end{array}$ & 12.50 & 353 & 191,179 & & & Chlorogenic acid \\
\hline & $\begin{array}{l}\text { Cryptochlorogenic acid } \\
\text { (4-caffeoylquinic acid) }\end{array}$ & 14.26 & 353 & 191,179 & & & $\begin{array}{l}\text { Cryptochlorogenic } \\
\text { acid }\end{array}$ \\
\hline & Coumaroylquinnic acid 1 & 16.01 & 337 & 191,163 & & & $p$-Coumaric acid \\
\hline & Quercetin diglucoside & 17.13 & 625 & $301,300,445$ & \multirow[t]{2}{*}{179,151} & & $\begin{array}{l}\text { Quercetin-3-O- } \\
\text { glucoside }\end{array}$ \\
\hline & Coumaroylquinnic acid 2 & 17.47 & 337 & 191,163 & & & $p$-Coumaric acid \\
\hline & Indole-3-acetylasparaginic acid & 21.01 & 289 & 245 & $116,85,74$ & & Gallic acid \\
\hline
\end{tabular}

$[\mathrm{M}-\mathrm{H}]^{-}$, pseudo-molecular ion identified in negative ion mode (first fragment number); $\mathrm{MS}^{2}-\mathrm{MS}^{4}$, fragments that were further fragmented.

Here, 30 compounds were identified and quantified across these three crop vegetables of L. culinaris, L. sativa, and S. lycopersicum, some of which are described for the first time in these crop vegetables in terms of the seeds, and all of which are described for the first time in the seedlings.

Figure 4 shows the production of the amino acid phenyl butryryl glutamine in $L$. culinaris and S. lycopersicum, and the 4-hydroxyphenylaoyl glucoside derivative in L. sativa. 
In S. lycopersicum, the content of phenyl butryryl glutamine decreased generally across these conditions during germination of the seeds, with indications of lower levels on the last day for the controls, K1 and K2. Instead, in L. culinaris (Figure 4B) the phenyl butryryl glutamine content generally increased during germination, although with no effects seen for the juglone treatments.

For the 4-hydroxyphenylaoyl glucoside derivative in L. sativa, there were no differences between these treatments in the early stages of germination, although some differences were seen during the shoot growth for the last day of the measurements. Here, the 4-hydroxyphenylaoyl glucoside content significantly decreasing in the seedlings treated with $100 \mu \mathrm{M}$ control juglone, in contrast to the other treatments where the content was still increasing.

A

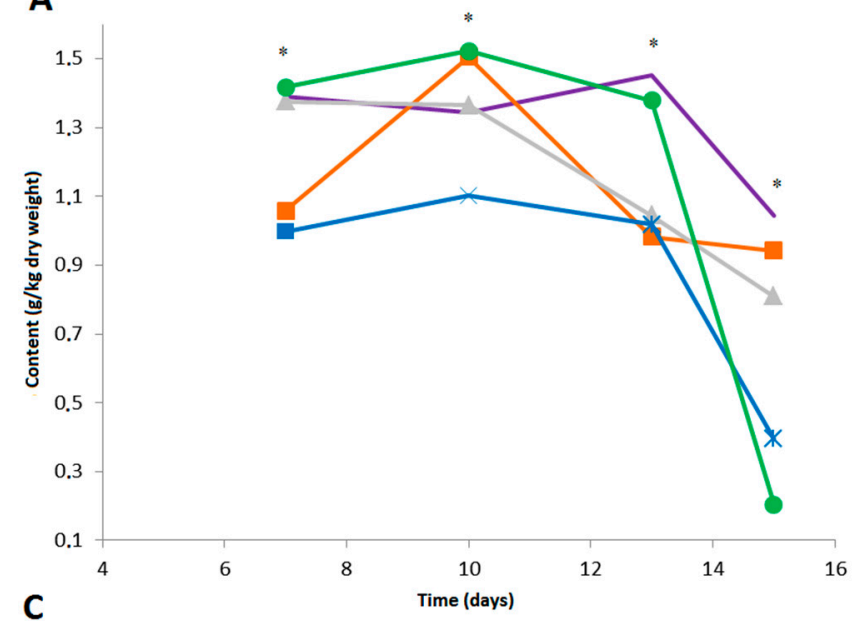

C

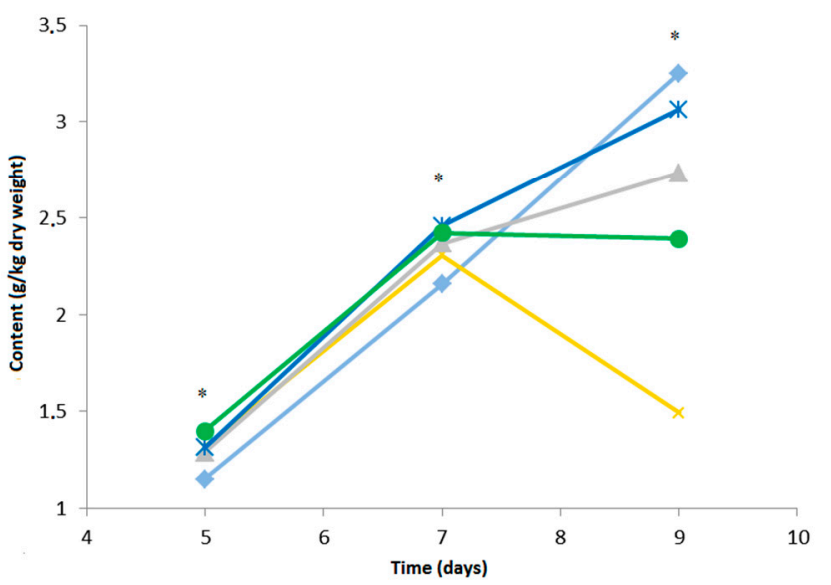

B

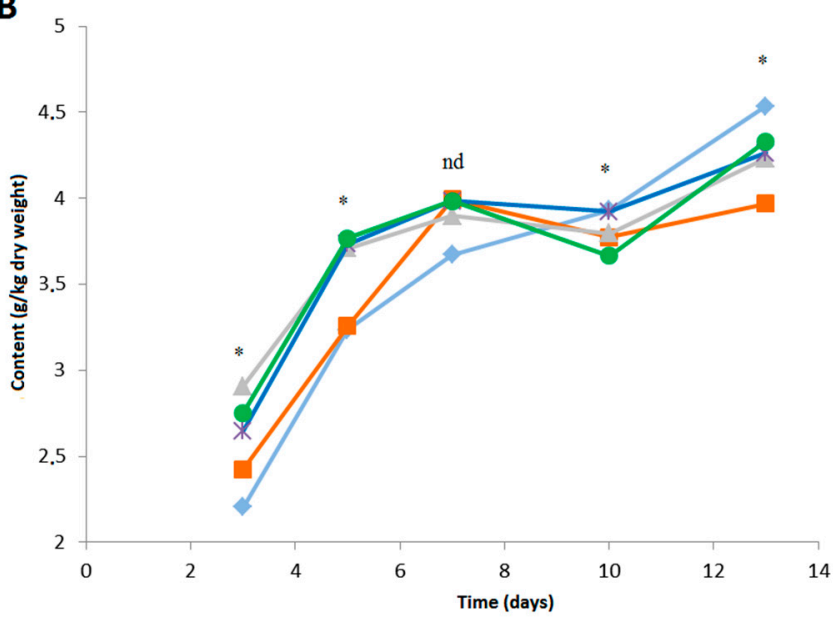

$\rightarrow 1$ mM leaf juglone

- $100 \mu \mathrm{M}$ leaf juglone

- $1 \mathrm{mM}$ control juglone

$\leftarrow 100 \mu \mathrm{M}$ control juglone

$-10 \mu \mathrm{M}$ control juglone

* control (K1)

$\rightarrow$ control (K2)

Figure 4. Effects of control juglone and known leaf extract juglone treatments on content of the amino acid phenyl butryryl glutamine (A,B) identified in S. lycopersicum (A) and L. culinaris (B), and the phenyl glucoside derivative 4hydroxyphenylaoyl glucoside in L. sativa (C). K1, extraction medium (vehicle); K2, water; *; are significantly different $(p<0.05)$; nd, not significantly different.

The responses during the germination and growth of these three crop vegetables to these various controls and juglone treatments seen for selected individual phenolic compounds are shown in Figure 5.

For caffeoyl hexaric acid 2 in S. lycopersicum, by the end of the germination and seedling growth, those treated with $1 \mathrm{mM}$ leaf juglone showed the highest content, followed by $1 \mathrm{mM}$ control juglone, with the lowest content in the K2 (water) control. For L. culinaris, a range of kaempferol derivatives were identified in particular (Table 1). Here, the largest effects were seen for the significantly greater contents of kaempferol trirhamnoside dihexoside and acylated kaempferol glycoside under the $1 \mathrm{mM}$ leaf juglone treatment. For the phenolics 
3,5-dicaffeoylquinic acid and caffeoyltartaric acid hexoside in L. sativa, the situation was similar to that seen for the phenyl butryryl glutamine content before, as both of these phenolics were significantly lower in the final analyses of the seedlings treated with $100 \mu \mathrm{M}$ control juglone.

In conclusion, for this range of secondary metabolites the leaf juglone showed effects on S. lycopersicum and L. culinars and $100 \mu \mathrm{M}$ juglone had effects on L. sativa.

A

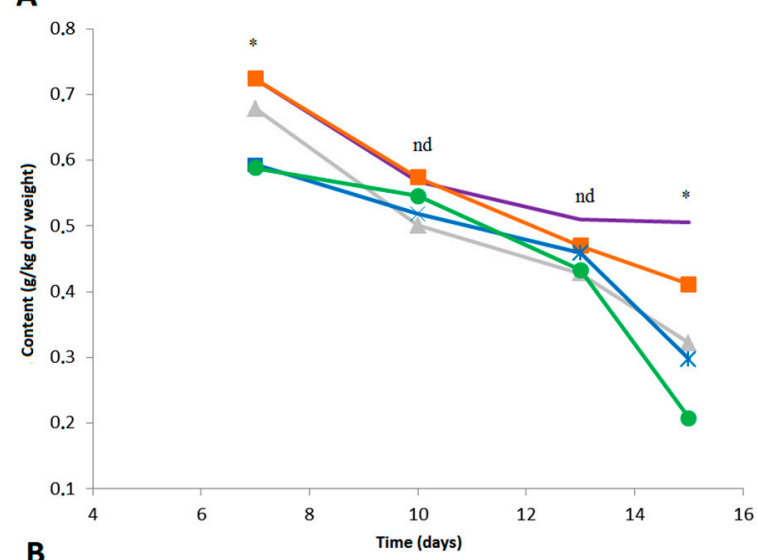

$\rightarrow 1 \mathrm{mM}$ leaf juglone

- $100 \mu \mathrm{M}$ leaf juglone

-"- $1 \mathrm{mM}$ control juglone

$\leftarrow 100 \mu \mathrm{M}$ control juglone

$-10 \mu \mathrm{M}$ control juglone

* control (K1)

$\rightarrow$ control (K2)

B
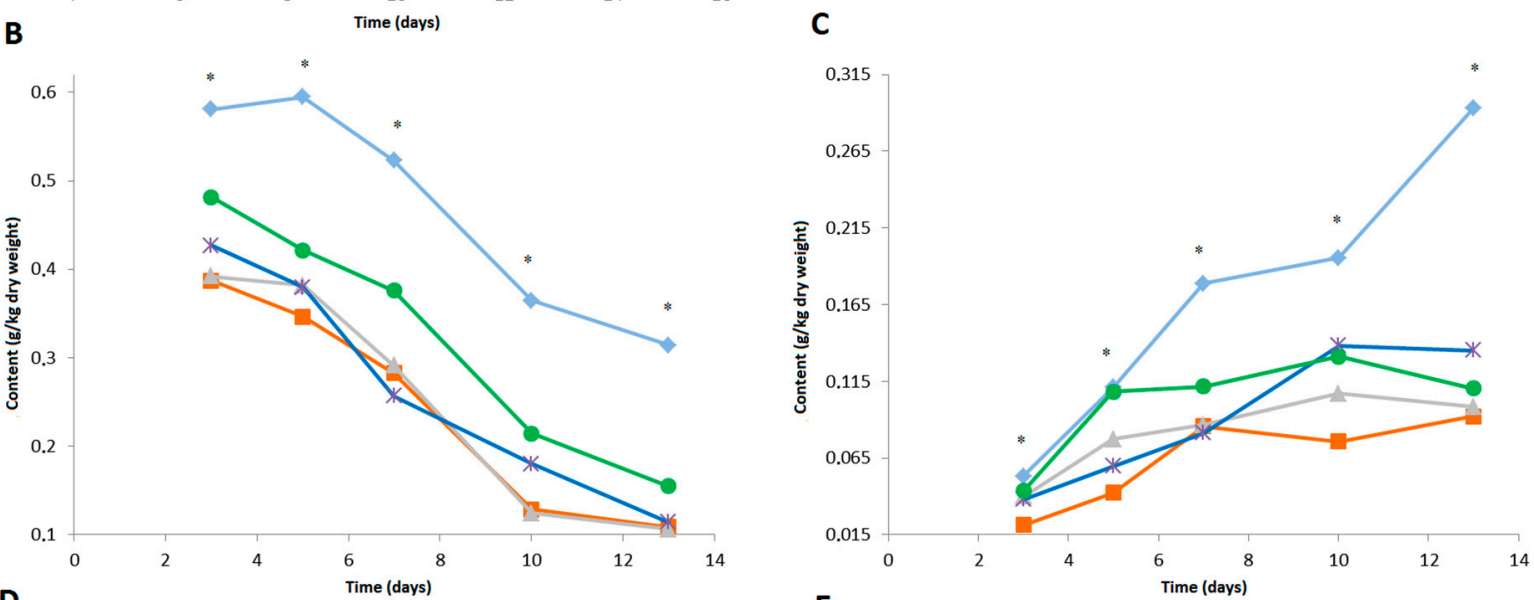

D

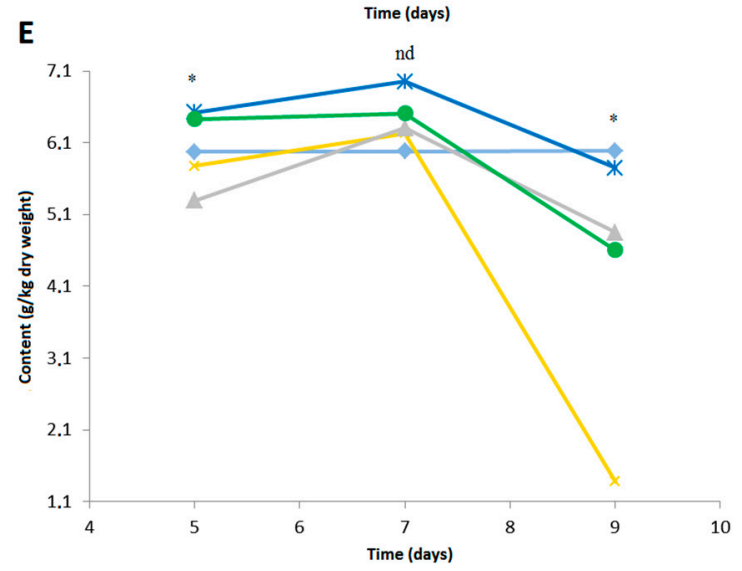

Figure 5. Effects of control juglone and known leaf extract juglone treatments on content of selected individual phenolic compounds identified, as caffeoyl hexaric acid 2 in S. Lycopersicum (A), kaempferol trirhamnoside dihexoside 1 (B) and kaempferol glycoside acylated 2 (C) in L. culinaris, and 3.5-dicaffeoylquinic acid (D) and caffeoyltartaric acid hexoside (E) in L. sativa. K1, extraction medium (vehicle); K2, water; *; are significantly different $(p<0.05)$; nd, not significantly different. 


\section{Discussion}

\subsection{Germination and Growth}

The effects of the same concentrations of the control juglone and leaf juglone treatments were not the same across these crop vegetables, as has been indicated in previous studies $[1,11]$. This suggests that each of these crop vegetables studied has its own response to the allelochemicals.

Juglone is not expected to be the only allelochemical present in J. regia. This is shown here in terms of the inhibitory effects against seed germination, where the $1 \mathrm{mM}$ control juglone would be expected to have the same effects as the $1 \mathrm{mM}$ leaf juglone. However, the germination of the seeds of $S$. lycopersicum, B. rapa var. japonica, and V. locusta was more affected by $1 \mathrm{mM}$ leaf juglone, and surprisingly, germination of L. sativa was only affected by $1 \mathrm{mM}$ control juglone, and not by $1 \mathrm{mM}$ leaf juglone. This suggests that the walnut leaf extract contains specific phenolic or other substance(s) that can stimulate seed germination in some species and inhibit seed germination of others [15]. Furthermore, it would thus be recommended and more meaningful if future studies not only examine and apply an individual allelochemical, but also use a leaf, root, or other extract in comparison. This would be especially important for defining lists of tolerance and susceptibility of plants, and it is needed to have a complete and clear picture of the effects of such allelochemicals.

A similar conclusion can be made in terms of seedling length as for seed germination, where there were greater inhibitory effects of $1 \mathrm{mM}$ leaf juglone compared to $1 \mathrm{mM}$ control juglone for S. lycopersicum, L. culinaris, and B. rapa var. japonica. Although there were no differences in L. culinaris when considering germination rates, the control juglone and leaf juglone did affect the total seedling length, which suggests that even if an allelochemical does not affect seed germination, it might still affect seedling length. The same was observed in L. sativa, where even though the seed germination was not affected by $1 \mathrm{mM}$ leaf juglone, the seedling length was. This might be because different allelochemicals can affect different plants at different stages of their development, with some that affect only seed germination, while others affect plant growth at later stages $[15,16]$.

Apart from juglone, some other 1,4-naphthoquinones have shown phytotoxicity. This phytotoxicity of 1,4-naphthoquinones and juglone comes from the generation of reactive oxygen species and glutathione depletion, and possibly from impairment of the plasma membrane $\mathrm{H}^{+}$-ATPase. Rapid and irreversible growth inhibition can explain such effects on the plasma membrane $\mathrm{H}^{+}$-ATPase via alkylation, as has previously been reported [15].

Previous investigations into the effects of juglone have shown that juglone can have greater post-germination effects than those seen on seed germination itself [17]. This was also seen here for S. lycopersicum and L. culinaris, and the reason for this might be that the seeds are more biochemically equipped to neutralise reactive oxygen species [15].

Effects of the control juglone treatments were clearly seen here for shoot and root growth. As previously observed in Oryza sativa [15], these juglone solutions prepared with the pure compound had little or no effect on shoot length but strongly inhibited root length. It has been suggested that juglone leads to changes in gene transcription associated with cell growth, cell-wall formation, chemical detoxification, and abiotic stress responses, with rapid induction of reactive oxygen species [18]. In L. sativa, juglone was previously shown to induce oxidative damage to the root apical meristem through the generation of reactive oxygen species [19]. It has been suggested that metabolic differences between plant species, and perhaps even between the above-ground and below-ground organs of the same species, contribute to determining the susceptibility of plants to juglone [15].

\subsection{Secondary Metabolites}

The hydroxycinnamic acids identified here included: caffeic acid, neochlorogenic acid (3-caffeoylquinic acid), chlorogenic acid (trans-5-caffeoylquinic acid), and cryptochlorogenic acid (4-caffeoylquinic acid). These were identified through their fragmentation and the use of external standards. The caffeic acid derivatives were identified through their fragmentation pattern of $\mathrm{MS}^{\mathrm{n}}$ ion $m / z 179$ (caffeic acid-H), as reported by Vieira 
et al. [20], and the caffeoylquinic acid derivatives and caffeoyltartaric acid hexoside and 3,5-dicaffeoylquinic acid through their fragmentation patterns as reported by Abu-Reidah et al. [21] and Ribas-Agustí et al. [22]. Caffeoyl hexaric acids and coummaroylquinic acids were identified through their fragmentation patterns as reported by Larbat et al. [23].

The flavonols identified here included quercetin diglucoside, quercetin-3-O-glucoronide, and kaempferol derivatives, which were all identified through their fragmentation patterns as reported by Rodriguez-Perez et al. [24], Abu-Reidah et al. [21], and Troszyńska et al. [25], respectively. Fragmentation patterns with the loss of hexosyl (-162) and rhamnosyl (-146) residues were seen here, as reported by Troszyńska et al. [25].

Furthermore, dyhidroxybenzoic acid hexoside and lactucin-15-oxalate were identified through their fragmentation patterns as reported by Abu-Reidah et al. [21] and Sessa et al. [26], as for decatylosperuloside derivatives and indole-3-acetylasparaginic acid, as reported by Rodríguez-Pérez et al. [24] and Amessis-Ouchemoukh et al. [27]. The 4-hydroxyphenylaoyl glucoside amino-acid derivative was identified through its fragmentation pattern as reported by Abu-Reidah et al. [21], and phenyl butryryl glutamine was reported for the first time in L. culinaris and S. lycopersicum, according to the fragmentation pattern previously described by Tsugawa et al. [28].

For plants to survive and thrive under different environmental conditions, they need to produce secondary metabolites that help them to cope with a variety of biotic and abiotic stresses $[13,14,29]$. The individual phenolic compounds studied here were highest in the seedlings treated with $1 \mathrm{mM}$ leaf juglone for L. culinaris and L. sativa, and $100 \mu \mathrm{M}$ leaf juglone for S. lycopersicum, which is as expected due to the responses of the plants to these stress conditions. Such stresses typically increase the levels of phenolic compounds, which can act as defense mechanisms in plants [4]. Looking at the metabolic responses of $S$. lycopersicum and L. culinaris, we can see that they were similar for these juglone treatments. The leaf juglone affected the individual phenolic compounds that were at the highest levels among the crop vegetables studied. Interestingly, the control juglone did not appear to have any significant effects on the metabolism of two of these crop vegetables, although it had large effects on the metabolism of L. sativa. The L. sativa seedlings treated with $100 \mu \mathrm{M}$ control juglone showed a large drop in all of the secondary metabolites studied on the last day of the measurements. This would probably have led to plant collapse in the following days, which has been reported previously [15].

The greatest resistance to both the control juglone and the leaf juglone of the crop vegetables studied was seen for L. culinaris, which might be because the majority of the compounds in these seedlings were flavonols. The flavonols are typically mentioned in the context of phenolics responses to various diseases and stress conditions in plants, and they act as a barrier against herbivores and microbial pathogens, along with hydroxycinnamic acids $[13,30]$.

\section{Conclusions}

The effects of the juglone treatments as pure juglone solutions and leaf extracts were not the same across all of these crop vegetables, as previously reported [1,11]. Overall, this suggests that each of the crops studied has its own response to allelochemicals, and that juglone is not the only allelochemical present in this leaf extract from J. regia. Germination of S. lycopersicum, B. rapa var. japonica, and V. locusta was more affected by $1 \mathrm{mM}$ leaf juglone, and surprisingly, germination of L. sativa was more affected by $1 \mathrm{mM}$ control juglone. This further suggests that this walnut leaf extract (i.e., leaf juglone) contains specific phenolic substance(s) that stimulate seed germination in some species and inhibit seed germination in others. The effects of the juglone treatments were clearly seen in terms of the shoot and root growth. As previously observed [15], the control juglone (i.e., from the pure compound) had little or no effect on shoot length but strongly inhibited root length. It can thus be suggested that these metabolic differences between plant species, and perhaps even between the above-ground and below-ground organs of the same species, contribute to the susceptibility of these plants to juglone. 
The individual phenolic compounds studied were highest in the seedlings treated with $1 \mathrm{mM}$ leaf juglone for L. culinaris and L. sativa, and with $100 \mu \mathrm{M}$ leaf juglone in $S$. lycopersicum, which is expected due to the responses of plants to these stress conditions. The $1 \mathrm{mM}$ juglone had a large effect on the metabolism of L. sativa, where the seedlings treated with even $100 \mu \mathrm{M}$ juglone showed a drop in all of the secondary metabolites studied. The highest resistance to juglone of these crop vegetables studied was seen for L. culinaris, as both the pure solution and the leaf extract. This might be because the flavonols constitute the majority of the phenolics in this crop vegetable.

Supplementary Materials: The following are available online at https:/ / www.mdpi.com/article/10 .3390 /agriculture 11080784 /s1, Table S1. Germination of different seeds ( 50 seeds is $100 \%$ germination); Table S2. Length of the seedlings in different days of germination; Table S3. Root and shoot length of the seedlings of Solanum lycopersicum L. and Lens culinaris Medik. on the last day of the measurements; Table S4. Individual compounds quantified in Lens culinaris Medik. at different days expressed as $\mathrm{g} / \mathrm{kg}$ dry weight; Table S5. Individual compounds quantified in Lactuca sativa L. at different days expressed as $\mathrm{g} / \mathrm{kg}$ dry weight; Table S6. Individual compounds quantified in Solanum lycopersicum L. at different days expressed as $\mathrm{g} / \mathrm{kg}$ dry weight.

Author Contributions: Conceptualization, A.M., R.V. and A.S.; methodology, A.M.; software, A.M.; validation, A.S. and R.V.; formal analysis, A.M. and T.Z.; investigation, A.M. and T.Z.; resources, A.M. and M.H.; data curation, A.M.; writing—original draft preparation, A.M.; writing—review and editing, A.S., R.V. and M.H.; visualization, A.M., R.V., T.Z. and A.S.; supervision, R.V. and A.S.; project administration, M.H. and R.V.; funding acquisition, R.V. and M.H. All authors have read and agreed to the published version of the manuscript.

Funding: This study was funded by the Slovenian Research Agency (ARRS) as part of programme P4-0013-0481.

Institutional Review Board Statement: Not applicable.

Informed Consent Statement: Not applicable.

Data Availability Statement: Part of the data presented in this study are available in Supplementary Materials here. The remaining data presented in this study are available on request from the corresponding author. The remaining data are not publicly available due to privacy. The data presented in this study are available on reasonable request from the corresponding author.

Conflicts of Interest: The authors declare that they have no known competing financial interests or personal relationships that could appear to have influenced the work reported here.

\section{References}

1. Ercisli, S.; Turkkal, C. Allelopathic effects of juglone and walnut leaf extracts on growth, fruit yield and plant tissue composition in strawberry cvs. 'Camarosa' and 'Sweet Charlie'. J. Hortic. Sci. Biotechnol. 2005, 80, 39-42. [CrossRef]

2. Strugstad, M.; Despotovski, S. A summary of extraction, synthesis, properties, and potential uses of juglone: A literature review. J. Ecosyst. Manag. 2012, 13,1-16.

3. Duroux, L.; Delmotte, F.M.; Lancelin, J.-M.; Kéravis, G.; Jay-Allemand, C. Insight into naphthoquinone metabolism: $\beta$-glucosidasecatalysed hydrolysis of hydrojuglone $\beta$-d-glucopyranoside. Biochem. J. 1998, 333, 275-283. [CrossRef]

4. Medic, A.; Jakopic, J.; Solar, A.; Hudina, M.; Veberic, R. Walnut (J. regia) Agro-Residues as a Rich Source of Phenolic Compounds. Biology 2021, 10, 535. [CrossRef] [PubMed]

5. Nour, V.; Trandafir, I.; Cosmulescu, S. HPLC Determination of Phenolic Acids, Flavonoids and Juglone in Walnut Leaves. J. Chromatogr. Sci. 2012, 51, 883-890. [CrossRef] [PubMed]

6. Sina Niculina, C.; Ion, T.; Gheorghe, A.; Adrian, B. Juglone Content in Leaf and Green Husk of Five Walnut (Juglans regia L.) Cultivars. Not. Bot. Horti Agrobot. Cluj. Napoca. 2011, 39. [CrossRef]

7. de Scisciolo, B.; Leopold, D.J.; Walton, D.C. Seasonal patterns of juglone in soil beneath Juglans nigra (black walnut) and influence of J. nigra on understory vegetation. J. Chem. Ecol. 1990, 16, 1111-1130. [CrossRef] [PubMed]

8. Kocacë Aliskan, I.; Terzi, I. Allelopathic effects of walnut leaf extracts and juglone on seed germination and seedling growth. J. Hortic. Sci. Biotechnol. 2001, 76, 436-440. [CrossRef]

9. Rietveld, W.J. Allelopathic effects of juglone on germination and growth of several herbaceous and woody species. J. Chem. Ecol. 1983, 9, 295-308. [CrossRef] [PubMed] 
10. Zubay, P.; Kunzelmann, J.; Ittzés, A.; Németh Zámboriné, É.; Szabó, K. Allelopathic effects of leachates of Juglans regia L., Populus tremula L. and juglone on germination of temperate zone cultivated medicinal and aromatic plants. Agrofor. Syst. 2021, 95, 431-442. [CrossRef]

11. Funk, D.T.; Case, P.J.; Rietveld, W.J.; Phares, R.E. Effects of Juglone on the Growth of Coniferous Seedlings. For. Sci. 1979, 25, 452-454. [CrossRef]

12. Medic, A.; Jakopic, J.; Hudina, M.; Solar, A.; Veberic, R. Identification and quantification of the major phenolic constituents in Juglans regia L. peeled kernels and pellicles, using HPLC-MS/MS. Food Chem. 2021, 352, 129404. [CrossRef]

13. Oh, M.-M.; Carey, E.E.; Rajashekar, C.B. Environmental stresses induce health-promoting phytochemicals in lettuce. Plant. Physiol. Biochem. 2009, 47, 578-583. [CrossRef] [PubMed]

14. Wink, M. Introduction: Biochemistry, Role and Biotechnology of Secondary Metabolites (From APR Volume 3). In Annual Plant Reviews Online; Wiley: Hoboken, NJ, USA, 2018; pp. 1-17. [CrossRef]

15. Islam, A.K.M.M.; Widhalm, J.R. Agricultural Uses of Juglone: Opportunities and Challenges. Agronomy 2020, 10, 1500. [CrossRef]

16. Kumagai, Y.; Shinkai, Y.; Miura, T.; Cho, A.K. The chemical biology of naphthoquinones and its environmental implications. Annu. Rev. Pharm. Toxicol. 2012, 52, 221-247. [CrossRef] [PubMed]

17. Segura-Aguilar, J.; Hakman, I.; Rydström, J. The Effect of 5OH-1,4-Naphthoquinone on Norway Spruce Seeds during Germination. Plant. Physiol. 1992, 100, 1955-1961. [CrossRef] [PubMed]

18. Chi, W.-C.; Fu, S.-F.; Huang, T.-L.; Chen, Y.-A.; Chen, C.-C.; Huang, H.-J. Identification of transcriptome profiles and signaling pathways for the allelochemical juglone in rice roots. Plant. Mol. Biol. 2011, 77, 591-607. [CrossRef] [PubMed]

19. Babula, P.; Vaverkova, V.; Poborilova, Z.; Ballova, L.; Masarik, M.; Provaznik, I. Phytotoxic action of naphthoquinone juglone demonstrated on lettuce seedling roots. Plant. Physiol. Biochem. 2014, 84, 78-86. [CrossRef]

20. Vieira, V.; Pereira, C.; Pires, T.C.S.P.; Calhelha, R.C.; Alves, M.J.; Ferreira, O.; Barros, L.; Ferreira, I.C.F.R. Phenolic profile, antioxidant and antibacterial properties of Juglans regia L. (walnut) leaves from the Northeast of Portugal. Ind. Crop. Prod. 2019, 134, 347-355. [CrossRef]

21. Abu-Reidah, I.M.; Contreras, M.M.; Arráez-Román, D.; Segura-Carretero, A.; Fernández-Gutiérrez, A. Reversed-phase ultrahigh-performance liquid chromatography coupled to electrospray ionization-quadrupole-time-of-flight mass spectrometry as a powerful tool for metabolic profiling of vegetables: Lactuca sativa as an example of its application. J. Chromatogr. A 2013, 1313, 212-227. [CrossRef]

22. Ribas-Agustí, A.; Gratacós-Cubarsí, M.; Sárraga, C.; García-Regueiro, J.-A.; Castellari, M. Analysis of Eleven Phenolic Compounds Including Novel p-Coumaroyl Derivatives in Lettuce (Lactuca sativa L.) by Ultra-high-performance Liquid Chromatography with Photodiode Array and Mass Spectrometry Detection. Phytochem. Anal. 2011, 22, 555-563. [CrossRef]

23. Larbat, R.; Paris, C.; Le Bot, J.; Adamowicz, S. Phenolic characterization and variability in leaves, stems and roots of Micro-Tom and patio tomatoes, in response to nitrogen limitation. Plant Sci. 2014, 224, 62-73. [CrossRef] [PubMed]

24. Rodríguez-Pérez, C.; Gómez-Caravaca, A.M.; Guerra-Hernández, E.; Cerretani, L.; García-Villanova, B.; Verardo, V. Comprehensive metabolite profiling of Solanum tuberosum L. (potato) leaves by HPLC-ESI-QTOF-MS. Food Res. Int. 2018, 112, 390-399. [CrossRef]

25. Troszyńska, A.; Estrella, I.; Lamparski, G.; Hernández, T.; Amarowicz, R.; Pegg, R.B. Relationship between the sensory quality of lentil (Lens culinaris) sprouts and their phenolic constituents. Food Res. Int. 2011, 44, 3195-3201. [CrossRef]

26. Sessa, R.A.; Bennett, M.H.; Lewis, M.J.; Mansfield, J.W.; Beale, M.H. Metabolite profiling of sesquiterpene lactones from lactuca species: Major latex components are novel oxalate and sulfate conjugates of lactucin and its derivatives. J. Biol. Chem. 2000, 275, 26877-26884. [CrossRef]

27. Amessis-Ouchemoukh, N.; Abu-Reidah, I.M.; Quirantes-Piné, R.; Rodríguez-Pérez, C.; Madani, K.; Fernández-Gutiérrez, A.; Segura-Carretero, A. Tentative Characterisation of Iridoids, Phenylethanoid Glycosides and Flavonoid Derivatives from Globularia alypum L. (Globulariaceae) Leaves by LC-ESI-QTOF-MS. Phytochem. Anal. 2014, 25, 389-398. [CrossRef]

28. Tsugawa, H.; Nakabayashi, R.; Mori, T.; Yamada, Y.; Takahashi, M.; Rai, A.; Sugiyama, R.; Yamamoto, H.; Nakaya, T.; Yamazaki, M.; et al. A cheminformatics approach to characterize metabolomes in stable-isotope-labeled organisms. Nat. Methods 2019, 16, 295-298. [CrossRef]

29. Kumar, A.; Memo, M.; Mastinu, A. Plant behaviour: An evolutionary response to the environment? Plant Biol. 2020, 22, 961-970. [CrossRef]

30. Treutter, D. Significance of Flavonoids in Plant Resistance and Enhancement of Their Biosynthesis. Plant Biol. 2005, 7, 581-591. [CrossRef] [PubMed] 